western with the goodies-the journalists and certain doctors - shooting it out with the baddies-the manufacturers and the remainder of the medical profession. This is not the way to treat a serious communal problem to which there is no entirely satisfactory answer.

D. M. Potrs

\section{ANTHROPOLOGY IN INDIA}

\section{Urgent Research in Social Anthropology}

Proceedings of a Conference. Edited by Behari L. Abbi and Satish Saberwal. (Transactions of the Indian Institute of Advanced Study, Vol. 10.) Pp. ix +235 . (Indian Institute of Advanced Study: Simla, 1969.) Rs30; \$11; 70s.

THE government of independent India has not found it necessary or indeed prudent to follow the example of its British predecessor, which retreated every year from the hot season in the plains to the bracing hill climate of Simla, that scedy simulacrum of English suburbia. Instead, Simla has become a place of scholarly reflexion and researeh, with the establishment there of the Indian Institute of Advanced Study. This volume records the proceedings of a conference at the institute, to which a number of Indian and foreign anthropologists were invited. The papers submitted to the conference have bcen printed in full, although the summary of the discussions is somewhat brief, even cursory.

The main aim was to establish priorities in research. In the social as well as in tho natural sciences, what seems most urgent to research workers does not always scem so to politicians and bureaucrats. Yet anthropology seems to be in peculiar need of official support in India: on the one hand, it has not been as strongly based in universities as the more traditional disciplines; on the other hand, when official thinking has been dominated by the nceds of development, public funds have flowed more freely towards economies.

There are, however, some fields in which the needs of politics and scholarship seem to coincide. Anthropologists have long been particularly interested in hill and forest tribes, and several contributors are at pains to emphasize the urgency of continued research on them for reasons of national defence and national unity. But even here there is a difficulty: the smaller tribes whose individuality is most threatened by modernization, and who therefore seem of moro urgent intcrest to anthropologists, are of less interest to politicians and administrators than bigger tribes living near frontiers or in disturbed arcas. What is, however, often called salvage anthropology-the recording of tribal customs before they disappear-did not commend itself to all the contributors as the most urgent task. New fields were suggested both on scholarly and on governmental grounds - for example, the results of economic and social policies, and the processes of urbanization.

In such regions, anthropology, sociology and other disciplines meet, and porhaps the most interesting suggestions in this volume are for research of cross. disciplinary and cross-cultural significance. As a historian, I am increasingly aware of the need both for the terminological refinement that can be expected frorn the meeting of different disciplines and also for comparative studies of analogous processes of change in different countries. If Asia and Africa are to be more widely studied in the west, we must consider how far a vocabulary derived largely from western experionco can be applied to differont cultures and societies. The term middle class is an example; indeed, the careless manner in which it is often used of western societies might also be checked as a result of such analysis. Equally urgent is the need to identify comparable institutions and processes of ehange in different societies.

\section{FACTORS IN VIGILANCE}

\section{Human Vigilance Performance}

By D. R. Davies and G. S. Tune. Pp. 291.

Press: London, February 1970.) 85s.

(Staples

Detecting and making appropriate reactions to small and infrequent changes in tho environment during long periods is often both a boring and an extremely exacting business. Nevertheless, people in all sorts of situations ranging from driving a car to watchkeeping and industrial inspection have to perform vigilance tasks, and will no doubt continue to do so at least until automatic pattern recognition is a good deal further advanced than it is at present. In this book, Davies and Tune have set out to review the many factors affecting the efficiency of vigilance performance, which in some situations, such as inspection of banknotes and stamps, can reach near perfection, while in others, such as the monitoring of radar screens, it is often so bad that only a small fraction of the events watched for are detected.

Experimental study of vigilance has been encouraged by the importance of its industrial and military applications. In spite of this, the authors choose "not to emphasize this relevance, but rather to evaluate the contributions these [laboratory] studies have made to theory". The choice may be thought to be somewhat unfortunate, because it has involved almost complete omission of any discussion of the means by which this work can be put to fruitful industrial use. What this book does provide is a comprehensive survey of the laboratory investigation of vigilance.

After a first chapter on definitions and methods of measurement comes a brief historical survey tracing the development of the subject from the famous pioneering work of Mackworth published in the five years following the last war. The body of the book is in the next four chapters, which review in turn the effects of signal characteristics, the variables relating to the design of the task, the type of subjects uscd, and the environmental manipulations which improve or impair performance. The final chapter is a discussion of how far the many factors aftecting the overall level of efficiency and its decline in the course of a session can be accounted for by four different types of theory. My own efficiency in finding printing errors no doubt underwent the normal rapid decrement. Early in the session, however (page 10), it was heartening to see that "carousal" had been introduced as a construct in theories of vigilance.

The book's main strength is in presenting the large body of experimental work on vigilance for tho first time in a methodically organized way that makes for easy reference. Helpful summaries of the main points of each chapter are included. The style often seems rather constrained by the concern of the authors to summarize or just mention some 600 experimental papers. As a review of an area containing much work of intrinsic interest the book is, however, welcome.

KFITH OATLEY

\section{GALENIC DOCTRINES}

\section{Galen on Sense Perception}

His Doctrines, Observations and Experiments on Vision, Hearing, Touch and Pain, and their Historical Sources. By R. Siegel. Pp. xii +216. (Karger: Basel and New York, 1970. Distributed in the UK by Academic Press, London.) $64 \mathrm{Sw}$. francs; $128 \mathrm{~s} ; \$ 15.35$.

IN 1968, Dr Siegel published his account of Galcn's system of physiology and medicine and at that time promised a second volume dealing exclusively with the writings on sense perception. As the subtitle states, this further book deals with Galen's doctrines, observations, and exporiments on vision, hearing, smoll, taste, touch and pain, and their historical sources. In the case of each sonse, Siegel 